\title{
EFEITOS DA SALINIDADE E DIETA ALIMENTAR SOBRE OS COPÉPODES PSEUDODIAPTOMUS RICHARDI E NOTODIAPTOMUS INCOMPOSITUS EM ESTUDOS DE LABORATÓRIO
}

\author{
KAMINSKI ${ }^{*}$, S. M.; BERSANO², J. G. F. \& AMARAL ${ }^{1}$, W. J. A. \\ ${ }^{1}$ Instituto de Oceanografia, Universidade Federal do Rio Grande, Caixa Postal 474, Rio Grande, RS, \\ 96.201-900 - Brasil. \\ *Corresponding author: sonia@kaminski.org.br \\ ${ }^{2}$ Centro de Estudos do Mar, Universidade Federal do Paraná, Caixa Postal 50.002, Pontal do Paraná \\ Pontal do Sul, PR, 83.255-000.
}

\begin{abstract}
Kaminski, S. M.; Bersano, J. G. F. \& Amaral, W. J. A. Efeitos da salinidade e dieta alimentar sobre os copépodes Pseudodiaptomus richardi e Notodiaptomus incompositus em estudos de laboratório. Braz. J. Aquat. Sci. Technol. 13(1):25-36. ISSN 1808-7035. In this study the effects of different salinities and algal diets on number of eggs produced by the copepods Pseudodiaptomus richardi and Notodiaptomus incompositus, were evaluated under controlled laboratory conditions. For P. richardi the development time from newly hatched nauplii to adults was compared for the three salinities under saturating food conditions. This species showed to be very tolerant to a wide range of salinities presenting the same growth rate from nauplii to adults when reared at salinities (S) 5,15 and 30 . The survivorship was $40,51 \pm 7,6 \%$ in average, with a maximum of $49 \%$ at $S=15$. The mean development time was 16 days $\left(20^{\circ} \mathrm{C}\right.$ ), with no differences (ANOVA, $\left.p>0,05\right)$ among the three salinities tested. The egg production values where in average higher $(p<0,05)$ for females reared at tested salinity since nauplii stages, when compared to acclimated females captured from the natural environment. The copepod $N$. incompositus showed oligohaline characteristics since adults of this species presented total mortality at $S=15$. The survivorship increased with the decrease of salinity, being $20 \%$ at $S=10$ and $79 \%$ at $S=1$. There was no clutch production of $N$. incompositus at $S=10$, whereas it was very low at salinities 5 and 1. Regarding the diets tested there was no significant differences (ANOVA, $p>0.05$ ) among the algae evaluated (Isochrysis galbana, Thalassiosira weissflogii, Chaetoceros muelleri and mixed diet). However the number of eggs produced found for $P$. richardi were in average twelve times higher than those observed for $N$. incompositus. The results of this study indicate that $P$. richardi is a very tolerant species, being well adapted for the constant fluctuating conditions of salinity and food composition usually found in estuaries and coastal areas.
\end{abstract}

Keywords: Copepods, experiments, growth, eggs produced.

\section{INTRODUÇÃO}

Diferenças geográficas na distribuição e composição de organismos zooplanctônicos podem estar associadas com a capacidade de tolerância das espécies às variações de salinidade e também com a preferência por determinados intervalos halinos (Uye et al., 2000; Coyle \& Pinckuk, 2003). Variações nos gradientes de salinidade e de temperatura podem definir a composição e a estrutura de assembléias zooplanctônicas (Hoffmeyer, 2004), bem como a abundância e a biomassa (Coyle \& Pinckuk, 2003).

O Estuário da Lagoa dos Patos (ELP) - Rio Grande - RS ( $\left.32^{\circ} 00^{\prime} S, 51^{\circ} 59^{\prime} \mathrm{W}\right)$ é caracterizado por grandes variações de salinidade, as quais são determinadas principalmente pelo regime de ventos e taxas de precipitação (Garcia, 1997). Durante descargas de água doce e fortes ventos de nordeste o sistema se torna límnico, enquanto que durante períodos dominados por ventos de sudeste e baixa precipitação ocorre salinização no ambiente (Niencheski \& Baumgarten, 1997).

No ELP, a diversidade e a distribuição de espécies do zooplâncton estão intimamente ligadas às variações de salinidade (Montú, 1980; Duarte et al., 1991). Assim como observado para outras áreas costeiras, o zooplâncton do ELP é freqüentemente dominado pelos copépodes (Montú, 1980). Estes crustáceos representam um importante elo entre o fitoplâncton e níveis tróficos superiores de muitos ecossistemas aquáticos (Hopcroft \& Roff, 1998), além de serem atualmente visados para uso em atividades de aqüicultura, como alimento na fase larval de peixes e camarões (Shipp et al., 1999; Payne et al., 2001; McKinnon et al., 2003; Aman \& Altaff, 2004). 
Os copépodes Pseudodiaptomus richardi e Notodiaptomus incompositus, ocorrem freqüentemente em áreas do ELP (Montú \& Gloeden, 1986; Cardozo et al., 2007), sendo segundo Montú (1980), espécies eurihalinas e euritérmicas. Estas espécies estão entre as mais freqüentes no ELP e juntamente com Acartia tonsa, estão também entre as mais abundantes neste estuário (Kaminski et al., em preparação, a). Quanto à reprodução, ambas as espécies pertencem ao grupo de copépodes que carregam sacos ovígeros, ao contrário de Acartia tonsa que é desovante livre.

Estudos realizados em outros estuários do Brasil têm mostrado que a salinidade é um fator importante na regulação da composição, densidade e distribuição de espécies. No estuário do Rio Caeté (Região Amazônica, Norte do Brasil), P. richardi ocorre nas estações seca e chuvosa e apresenta correlação negativa entre salinidade e densidade, indicando que a espécie prefere águas pouco salinas (Magalhães et al., 2006). Gradientes longitudinais deste parâmetro também podem ser parcialmente responsáveis pela segregação espacial de certas espécies, assim como verificado por Lopes (1994) para P. richardi no estuário do Rio Guaraú (São Paulo - Brasil).

No ELP, a espécie Acartia tonsa é predominante em períodos mais salinos, enquanto $N$. incompositus apresenta suas maiores densidades em salinidades mais baixas (Montú, 1980; Rudorff, 2002), especialmente em situações onde esta condição se mantém por períodos prolongados (Kaminski et al., em preparação, b). Na área norte do Estuário, predominantemente límnica, Notodiaptomus incompositus é o copépode dominante (Duarte et al., 1991). Já P. richardi pode dominar várias áreas do estuário em condições mixohalinas.

A salinidade pode influenciar diretamente no tempo de desenvolvimento larval dos copépodes (Payne \& Rippingale, 2001; Devreker et al., 2007) e também afetar a fecundidade e a produção de ovos de algumas espécies de Acartia (Castro-Longoria, 2003; Cardozo, 2004; Milione \& Zeng, 2008).

Além dos fatores abióticos, um fator bastante importante a ser considerado quando se estuda a produção de ovos de copépodes, é o tipo de dieta alimentar, que pode exercer influência direta sobre a taxa de reprodução de copépodes (Kleppel, 1992; Irigoien et al., 2000).

Ao testar diferentes dietas para se determinar a produção máxima de ovos do Calanoida estuarino Gladioferens imparipes, Payne \& Rippingale (2000) encontraram bons resultados com as microalgas Isochrysis galbana e Chaetoceros muelleri, em vários critérios observados. Estas microalgas juntamente com Thalassiosira weissflogii vêm sendo bastante utilizadas em estudos de laboratório.
Informações acerca do tempo de desenvolvimento e medidas de crescimento são essenciais para se avaliar a dinâmica de populações e as taxas de produção dos copépodes (Uye, 1991). Estas informações podem ser obtidas principalmente através de bioensaios laboratoriais, que permitem uma maior compreensão sobre fatores bióticos e abióticos que afetam a distribuição de determinadas espécies de copépodes em diferentes ambientes.

O presente estudo teve por objetivos: 1.) avaliar em laboratório a influência de diferentes salinidades sobre o número de ovos produzidos por postura dos copépodes Pseudodiaptomus richardie Notodiaptomus incompositus e também, sobre as taxas de crescimento de P. richardi; 2.) determinar o efeito de diferentes dietas algais sobre o número de ovos produzidos por postura para as duas espécies em questão, a fim de verificar o potencial reprodutivo das mesmas sob condições de laboratório.

\section{MATERIAL E MÉTODOS}

\section{Obtenção dos estoques de fitoplâncton e zooplâncton}

Neste estudo foram utilizadas as microalgas Isochrysis galbana, Thalassiosira weissflogii e Chaetoceros muelleri, cujos inóculos foram fornecidos pelo Laboratório de Fitoplâncton e Microorganismos Marinhos da Universidade Federal de Rio Grande (FURG). As três microalgas foram cultivadas no Laboratório de Zooplâncton da FURG segundo o método "Batch" de cultivo. Este método consiste em diluições sucessivas durante a fase exponencial de crescimento para a obtenção de grande volume de cultivo em alta densidade celular. Para cada diluição as células foram contadas diariamente em câmara de Neubauer sob microscópio óptico, sendo os cultivos sempre mantidos em fase exponencial de crescimento.

Os copépodes utilizados neste estudo foram obtidos ao longo de várias coletas realizadas em diferentes áreas do Estuário da Lagoa dos Patos, com rede de zooplâncton de $1,5 \mathrm{~m}$ de comprimento, 0,3 m de diâmetro de boca e malha de 200 um com copo cego, mediante arrastos horizontais superficiais de 3 a $5 \mathrm{~min}$. Todos os indivíduos capturados foram levados para o Laboratório de Zooplâncton da FURG e mantidos em água do ambiente, com aeração suave até o momento da triagem. Após cada coleta, centenas de indivíduos machos e fêmeas adultos de Notodiaptomus incompositus e Pseudodiaptomus richardi foram separados individualmente com pipeta de Pasteur sob microscópio estereoscópico, a fim de se iniciar os estoques de copépodes para os experimentos. A espécie $N$. incompositus foi coletada principalmente em áreas 
com salinidade próxima a 0 e 5 , enquanto $P$. richardi foi coletada em salinidades que variaram entre 0 e 30 , especialmente entre 10 e 20.

Os organismos separados foram estocados inicialmente em frascos de $2 \mathrm{~L}$, com água do mar filtrada em $3 \mu \mathrm{m}$ e/ou diluída até a salinidade do ambiente de coleta com água mineral (Pedras do Sul - Pedras Altas, RS), e mantidos em uma sala de cultivo com temperatura de $20^{\circ} \mathrm{C}$, cada frasco recebendo suave aeração e alimento em excesso, composto por mistura das microalgas cultivadas. A salinidade (S) foi aumentada ou diminuída gradativamente para $S 15$ e $S 30$ nos cultivos de $P$. richardi e para $S 5$ nos cultivos de $N$. incompositus, sendo estas as salinidades mantidas nos cultivos estoques. À medida que começaram a se reproduzir, os copépodes foram sendo transferidos para baldes ( $20 \mathrm{~L}$ inicialmente e após para $80 \mathrm{~L}$ ). Periodicamente, outras coletas no ambiente foram realizadas para a captura de novos organismos, sendo esses também isolados e adicionados aos cultivos para manutenção da diversidade genética.

\section{Experimentos de crescimento do copépode Pseudodiaptomus richardi}

O experimento de crescimento foi realizado nas salinidades 30 (S 30), 15 (S 15) e 5 (S 5). Foram utilizadas unidades experimentais (UE) constituídas de recipientes cilíndricos de vidro, com capacidade de 2,5 L. Estas foram mantidas dentro de uma sala de cultivo com temperatura e fotoperíodo controlados, $20^{\circ} \mathrm{C} \mathrm{e}$ 12:12 L/E (luz /escuro), respectivamente. As UE receberam aeração individual e a salinidade foi controlada de acordo com o tratamento testado, sendo três repetições para cada tratamento (9 UE). A partir dos resultados deste teste foi definida a melhor salinidade para a espécie a ser utilizada nos testes de alimentação. Os organismos foram alimentados com I. galbana $\left(16.10^{4} \mathrm{cel} \mathrm{mL}^{-1}\right)$, e a partir do $5^{\circ}$ dia de cultivo foi adicionada também T. weissflogii $\left(2.10^{4} \mathrm{cel} \mathrm{mL}^{-1}\right)$ até o último dia de cultivo. As concentrações foram definidas a fim de fornecer no mínimo $1 \mathrm{mg} \mathrm{C} \mathrm{L-1}$, concentração considerada suficiente para garantir uma boa nutrição dos copépodes (Kiørboe et al., 1985). As microalgas foram escolhidas em função da adequabilidade de tamanho durante diferentes fases de desenvolvimento dos copépodes (Berggreen et al., 1988), bem como tendo em vista sucesso no cultivo de outras espécies com a utilização das mesmas (Cardozo, 2004; Kaminski, 2004).

Os cultivos experimentais foram iniciados a partir de náuplios obtidos dos estoques monoespecíficos mantidos anteriormente. Copépodes adultos foram separados do cultivo massivo com auxílio de peneira com malha de $300 \mu \mathrm{m}$, e colocados em baldes de $20 \mathrm{~L}$ contendo água na salinidade a ser testada e alimento em excesso. Após 24 horas foram coletados os náuplios eclodidos durante esse período, sendo separados dos adultos com tela de $150 \mu \mathrm{m}$, e após concentrados com tela de $45 \mu \mathrm{m}$ para separação sob microscópio estereoscópico. Foram separados 500 náuplios para cada UE contendo $2 \mathrm{~L}$ de água, obtendo-se uma densidade inicial de estocagem de 250 náuplios $\mathrm{L}^{-1}$.

Para acompanhar o desenvolvimento dos organismos da fase naupliar até a adulta, diariamente foram retiradas alíquotas das UE com amostrador tipo colher sueca. Do primeiro ao $12^{\circ}$ dia de cultivo foram retiradas alíqüotas de $60 \mathrm{~mL}$, e do $13^{\circ}$ dia até o final as alíquotas foram aumentadas para $160 \mathrm{~mL}$ (3\% e 8\% do volume da UE, respectivamente), para obtenção de um número de indivíduos suficiente para a estimativa de densidade e medidas de comprimento e largura. O tempo médio de desenvolvimento (TMD) foi estimado quando $50 \%$ dos organismos passaram para a fase adulta (Leandro et al., 2006).

Diariamente uma pequena amostra da água das UE era retirada para contagem de residual de algas e cálculo da quantidade a ser adicionada para manter a concentração desejada. A renovação de água foi feita diariamente, em torno de $30 \%$ do volume total, sendo sifonada água do fundo das UE utilizando-se um cano com malha de $100 \mu \mathrm{m}$ na parte inferior, evitando assim a passagem dos náuplios. Em seguida água nova era adicionada, na salinidade de cada tratamento, contendo microalgas na concentração desejada, para manter o volume e a concentração algal nas UE.

Organismos das alíquotas foram fixados em solução de formaldeído a 4\%, contados e guardados para posteriores medições. O experimento teve duração de 17 dias, sendo ao final todo conteúdo fixado em solução de formaldeído a 4\%, para cálculo de sobrevivência e da proporção de fêmeas e machos. Para cálculo da sobrevivência final foram considerados os organismos retirados nas alíquotas durante o experimento, sendo o valor de organismos retirados de cada UE somado ao número de organismos obtidos ao final do experimento.

As medições e contagem dos organismos foram realizadas sob microscópio estereoscópico provido de ocular micrométrica. Foram tomadas as medidas de comprimento total para os náuplios e do prossoma (cefalotórax) para copepoditos e adultos. Foram medidos de 10 a 90 organismos para cada dia de cultivo em cada tratamento, de acordo com sua abundância nas alíquotas.

Neste experimento foi observado o crescimento, a sobrevivência, a proporção de fêmeas e machos e o percentual de fêmeas ovígeras ao final do cultivo. 


\section{Experimentos para determinar o Número de Ovos Produzidos por Postura (NOP) e as taxas de Produção de Ovos (PO).}

Para determinar o tempo médio de incubação dos ovos pelas fêmeas (TI), foram realizados testes preliminares com duração de 120 horas, nas salinidades 5,15 e 30 , sendo alimentados com $2.10^{4} \mathrm{cel} \mathrm{mL}^{-1}$ de Thalassiosira weissflogii, e posteriormente, na salinidade 15 variando a alimentação, conforme especificado mais adiante nos testes sob diferentes dietas. Foram utilizadas 10 repetições para cada tratamento. Fêmeas e machos adultos foram separados a partir dos cultivos estoques, sendo incubados um casal por UE de 200 $\mathrm{mL}$, contendo água na salinidade, e um tubo de PVC com volume de $100 \mathrm{~mL}$ forrado com malha de $200 \mu \mathrm{m}$, permitindo a passagem dos náuplios mas não dos adultos, a fim de facilitar a observação. Foi observada a presença ou não de sacos ovígeros e de náuplios a cada 24 horas, quando observados náuplios e fêmeas ovadas no mesmo dia, considerou-se que ocorreu uma desova e uma nova postura nesse intervalo de 24 horas. A alimentação e a troca de água foram feitas diariamente no momento da observação.

O valor da taxa de Produção de Ovos (PO) foi obtido a partir do método de proporção de ovos, utilizando fórmula sugerida por Harris et al.(2000):

$\mathrm{PO}=\mathrm{NOP} / \mathrm{NF}$.TI

Onde a $\mathrm{PO}$ é igual ao quociente do número de ovos por postura (NOP) pelo produto do número de fêmeas (NF) e o tempo médio de incubação (TI).

Para o copépode $P$. richardi, a PO das fêmeas cultivadas desde ovos até adultas nas salinidades testadas, foi determinada a partir da contagem dos ovos dos sacos ovígeros das fêmeas ao final do experimento de crescimento. Neste experimento a alimentação consistiu de $16.10^{4} \mathrm{cel} \mathrm{\textrm {mL } ^ { - 1 }}$ de I. galbana mais $2.10^{4} \mathrm{cel}$ $\mathrm{mL}^{-1}$ de $T$. weissflogii, a qual estava sendo fornecida para os organismos ao final do experimento de crescimento, descrito anteriormente.

O NOP das fêmeas que passaram por aclimatação (na salinidade ou alimentação) foi determinado para as duas espécies. Para estes testes foram utilizados UE consistindo de frascos de vidro contendo 1000 e $600 \mathrm{~mL}$ de água, para $P$. richardi e $N$. incompositus, respectivamente, com temperatura e fotoperíodo controlados, $20^{\circ} \mathrm{C}$ e $12: 12 \mathrm{~L} / \mathrm{E}$, e recebendo suave aeração em cada UE. Foram estocados de 10 a 15 fêmeas adultas e de 5 a 10 machos em cada unidade experimental, respectivamente, sendo feitas 3 repetições para cada tratamento.

Nos testes de NOP em diferentes salinidades, a alimentação consistiu de T. weissflogii $\left(2.10^{4} \mathrm{cel} \mathrm{mL}^{-1}\right)$, e foram testadas 3 salinidades para cada espécie (9 UE por experimento). Para $P$. richardi foram testadas as salinidades 30,15 e 5 e para $N$. incompositus, devi- do a não sobrevivência da espécie nas salinidades $15 \mathrm{e}$ 30 , foram testadas as salinidades 1, 5 e 10.

Nos testes de NOP sob diferentes dietas, a salinidade para $P$. richardi foi $S 15$ e para $N$. incompositus foi $S 1$, tendo sido estas as melhores salinidades verificadas nos testes de salinidade para cada espécie. Foram testados quatro diferentes tratamentos (12 UE por experimento): dieta com Isochrysis galbana $\left(16.10^{4} \mathrm{cel} \mathrm{mL}^{-1}\right)$, dieta com Thalassiosira weissflogii $\left(2.10^{4} \mathrm{cel} \mathrm{mL}^{-1}\right)$; dieta com Chaetoceros muelleri $\left(14.10^{4} \mathrm{cel} \mathrm{mL}^{-1}\right)$ e dieta mista com as três espécies $\left(5.10^{4} \mathrm{cel} \mathrm{mL}{ }^{-1}+7.10^{3} \mathrm{cel} \mathrm{mL}^{-1}+5.10^{4} \mathrm{cel} \mathrm{mL}^{-1}\right.$, respectivamente). A concentração do alimento foi determinada de acordo com o biovolume das microalgas utilizadas e oferecida em volumes equivalentes (Hillebrand et al., 1999), sendo estimada para fornecer no mínimo $1 \mathrm{mg} \mathrm{C} \mathrm{L}^{-1}$ (Kiørboe et al., 1985).

Nos experimentos com $P$. richardi, fêmeas e machos adultos foram retiradas do cultivo estoque mantido a S 30, contendo organismos de idades variadas. Para a realização dos experimentos com $N$. incompositus foram utilizados organismos coletados no ambiente, visto que os organismos que estavam sendo mantidos no cultivo estoque com sucesso em S 5 (várias categorias populacionais) por 40 dias, morreram repentinamente devido a uma causa desconhecida.

As fêmeas das duas espécies foram aclimatadas nas diferentes salinidades ou dietas por um período de 72 horas ( 3 dias), tempo suficiente para completar o tempo de uma postura, conforme determinado nos testes preliminares. Após esse período, os organismos passaram por nova separação sob lupa, observando-se o estado dos organismos, e foram incubados novamente. Diariamente era contado o residual das algas e adicionado mais alimento para manutenção da concentração inicial.

Após 96 horas o material foi fixado em solução de formaldeído a $4 \%$ para posterior contagem dos ovos nos sacos ovígeros produzidos sob as condições de cada tratamento, sendo determinado o NOP, como ovos.saco-1 fêmea ${ }^{-1}$, para as duas espécies; e a PO, como ovos.fêmea ${ }^{-1} \mathrm{dia}^{-1}$, para $P$. richardi.

\section{Análise Estatística}

Os dados obtidos foram submetidos à Análise de Variância (ANOVA, uma via), sendo comparadas as médias obtidas para o tempo de crescimento, sobrevivência, e para o número médio de ovos produzidos por postura das espécies nos diferentes tratamentos. Quando observadas diferenças significativas entre as médias foi aplicado o teste de Tukey com nível de significância de 95\% (Centeno, 1999). 


\section{RESULTADOS}

\section{Experimento de Crescimento de Pseudodiaptomus richardi}

Em todas as salinidades atingiu-se sucesso de sobrevivência até a fase adulta, o tratamento com S 15 apresentou os melhores resultados de sobrevivência, sendo significativamente superior aos da $S 5(p<0,05)$, mas não apresentando diferença estatística em relação a S 30 (Figura 01).

A variação na densidade dos organismos de acordo com a fase de desenvolvimento foi semelhante em todos os tratamentos (Figura 02). A densidade dos náuplios declinou mais abruptamente até o $3^{\circ}$ dia de cultivo. No $5^{\circ}$ dia começaram a ser observados os primeiros copepoditos, sendo detectada uma queda de aproximadamente $50 \%$ da densidade inicial nas UE (132 a 160 organismos $\mathrm{L}^{-1}$ ). Durante a fase de copepoditos o declínio na densidade foi menos acentuado, estes representaram a maioria da população do $8^{\circ}$ ao $14^{\circ}$ dia, nas três salinidades. Organismos na fase adulta foram observados a partir do 13으 dia de cultivo e ao final do experimento representavam maioria da população em todos os tratamentos.

Os náuplios representaram $100 \%$ da população em todos os tratamentos até o $4^{\circ}$ dia, predominando até o $7^{\circ}$ dia na S $5(55,8 \%$, Figura 03-A) e até o 5 dia nas salinidades 15 e 30 (65\% e 88,7\%, respectivamente, Figura 03- B e C). Os copepoditos foram dominantes do $8^{\circ}$ ao $14^{\circ}$ dia (de 60 a 100\%), e adultos foram encontrados a partir do $13^{\circ}$ dia nas S 5 e S 15 e a partir do $14^{\circ}$ dia na S 30 . No tratamento de S 15, o tempo médio de desenvolvimetno (TMD) de náuplio a adulto foi de 15 dias (Figura 03-B), quando mais de $50 \%$ dos organismos do cultivo atingiram a fase adulta. Nas salinidades 5 e 30 o TMD foi de 16 dias (Figura 03- Ae C).

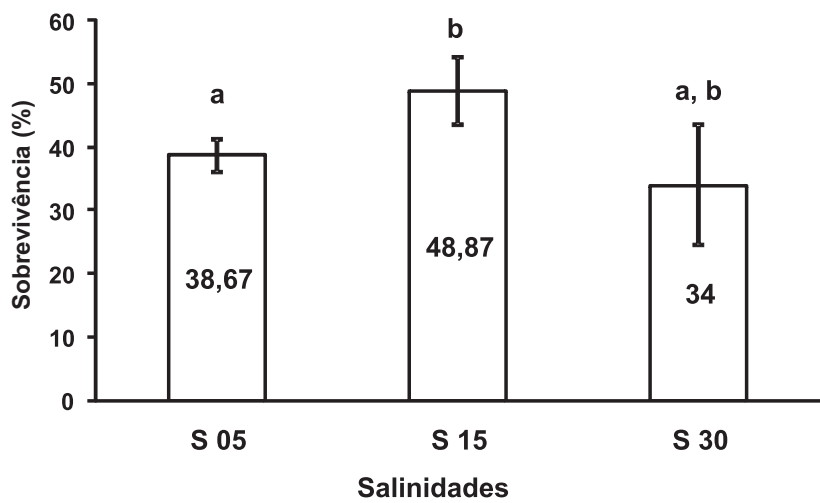

Figura 1 - Sobrevivência de Pseudodiaptomus richardi após 17 dias de cultivo em três diferentes salinidades. Médias e desvio padrões. Letras minúsculas diferentes denotam diferenças significativas entre os tratamentos $(p<0,05)$.
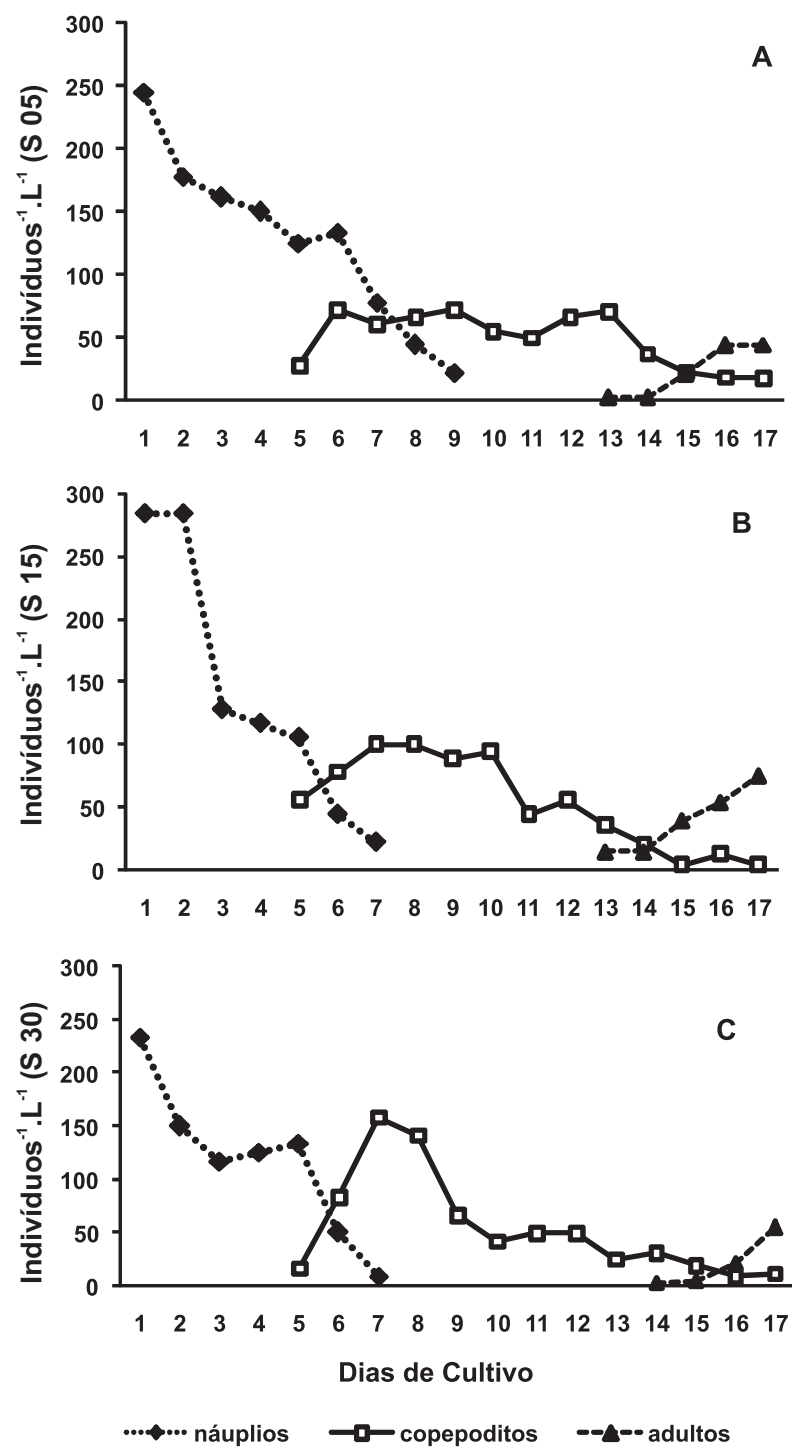

Figura 2 - Variação da densidade média das fases de desenvolvimento de Pseudodiaptomus richardi cultivado em diferentes salinidades: A- S 05; B- S 15; C- S 30.

Em relação as medidas de comprimento e largura, os valores de incremento diário durante o crescimento foram de 41,50 a $42,88 \mu \mathrm{m}$ para o comprimento e de 13,02 a 14,34 $\mu$ m para a largura, os valores de $R^{2}$ obtidos através da curva de crescimento linear foram próximos para todos os tratamentos, oscilando entre 0,89 e 0,93 para o comprimento e entre 0,78 e 0,87 para a largura (Figura 04- A, B e C).

As médias das medidas de largura e comprimento obtidas para cada fase de desenvolvimento estão descritas na tabela I. Não houve diferença estatística entre indivíduos que cresceram nas diferentes salinidades $(p>0,05)$, mas as medidas das fêmeas são maiores que as dos machos.

Considerando-se a proporção de sexos dos adultos, não houve diferença estatística entre machos e 
A

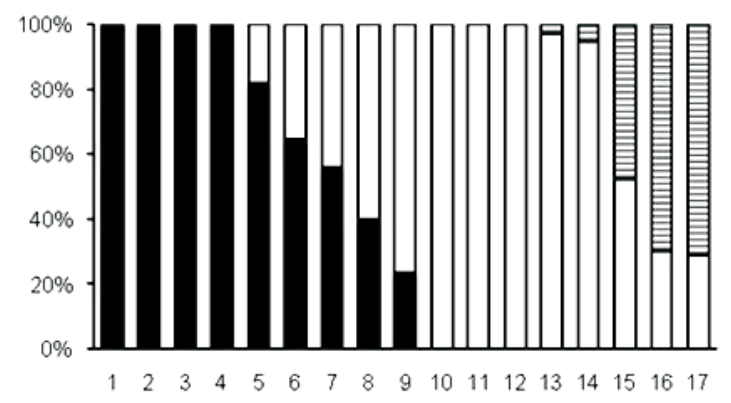

B

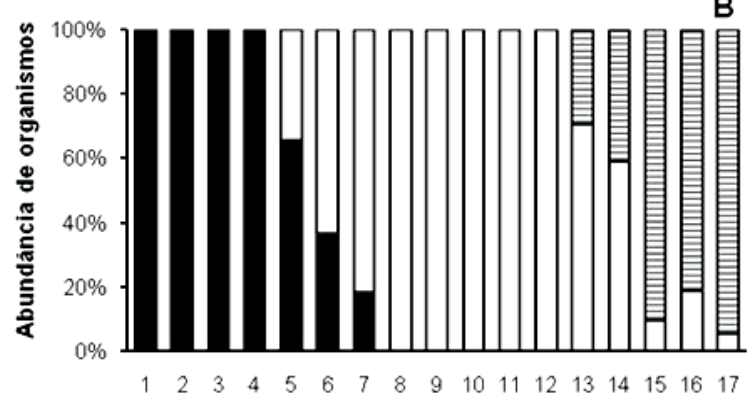

C

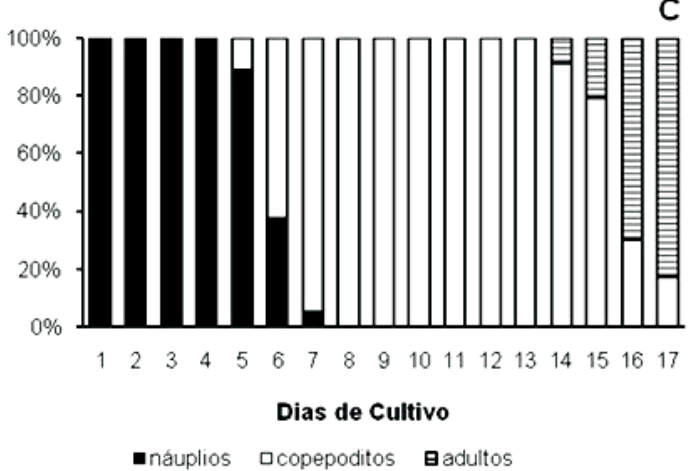

Figura 3 - Percentual das diferentes fases de desenvolvimento durante o cultivo de Pseudodiaptomus richardi. (A) S 5; (B) S 15; (C) $-\mathrm{S} 30 . \mathrm{T}^{\circ} \mathrm{C}=20^{\circ} \mathrm{C}$.

fêmeas para os tratamentos $(p>0,05)$. O número de fêmeas e machos foi estatisticamente igual em cada tratamento e entre os tratamentos (Figura 05- A). Quantificando-se o número de fêmeas ovígeras ao final dos experimentos de crescimento, não tendo sido levados em conta os sacos ovígeros que se desprenderam das fêmeas, a média percentual não apresentou diferença significativa $(p=0,126)$, mas foi aparentemente maior na salinidade 15 (Figura 05- B).

\section{Experimentos para determinar o Número de} Ovos Produzidos por Postura (NOP) e as taxas de Produção de Ovos (PO).

Testes Preliminares

O tempo de incubação dos ovos (TI) para $P$. richardi, determinado através de testes preliminares, foi em média 72 horas para todas as salinidades e dietas testadas. O número de incubações durante o experimento de 120 horas variou de acordo com o avanço
Tabela I - Valores máximo, mínimo e média (entre parênteses) das medidas para cada fase de Pseudodiaptomus richardi. Comprimento total para os náuplios e prossoma para copepoditos, machos e fêmeas. Valores médios entre todas as salinidades estudadas (S 5, S 15 e S 30).

\begin{tabular}{lcc}
\hline \hline & Comprimento $(\mu \mathrm{m})$ & Largura $(\mu \mathrm{m})$ \\
\hline Náuplios & $183-450(318)$ & $100-192(132)$ \\
Copepoditos & $350-950(624)$ & $133-350(236)$ \\
Fêmeas & $842-1108(992)$ & $317-433(372)$ \\
Machos & $709-908(834)$ & $242-325(287)$ \\
\hline \hline
\end{tabular}
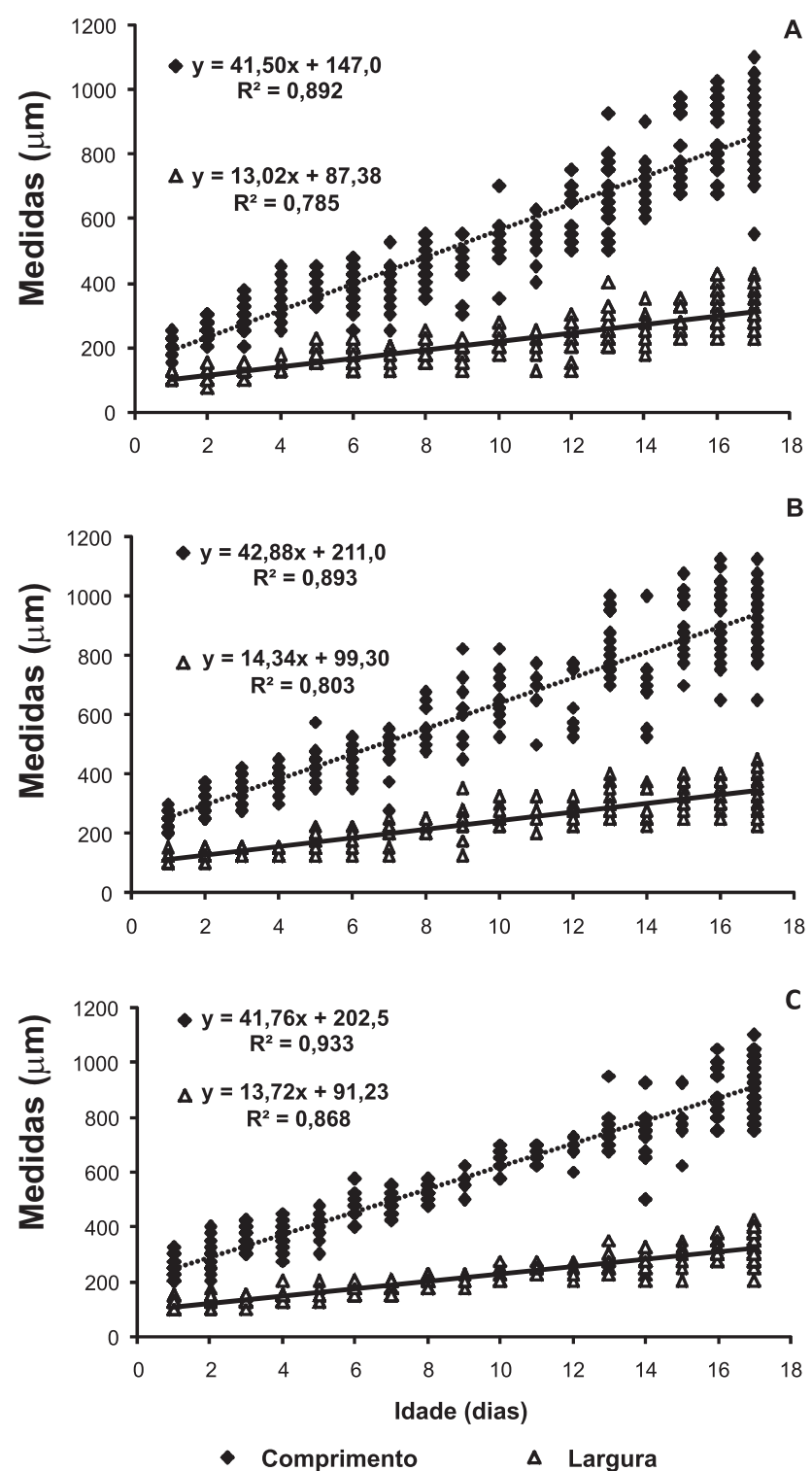

Figura 4 - Regressão linear entre medidas de crescimento (comprimento e largura) e idade para o copépode $P$. richardi cultivado em diferentes salinidade (A) S 5; (B) S 15 e (C) S 30. 

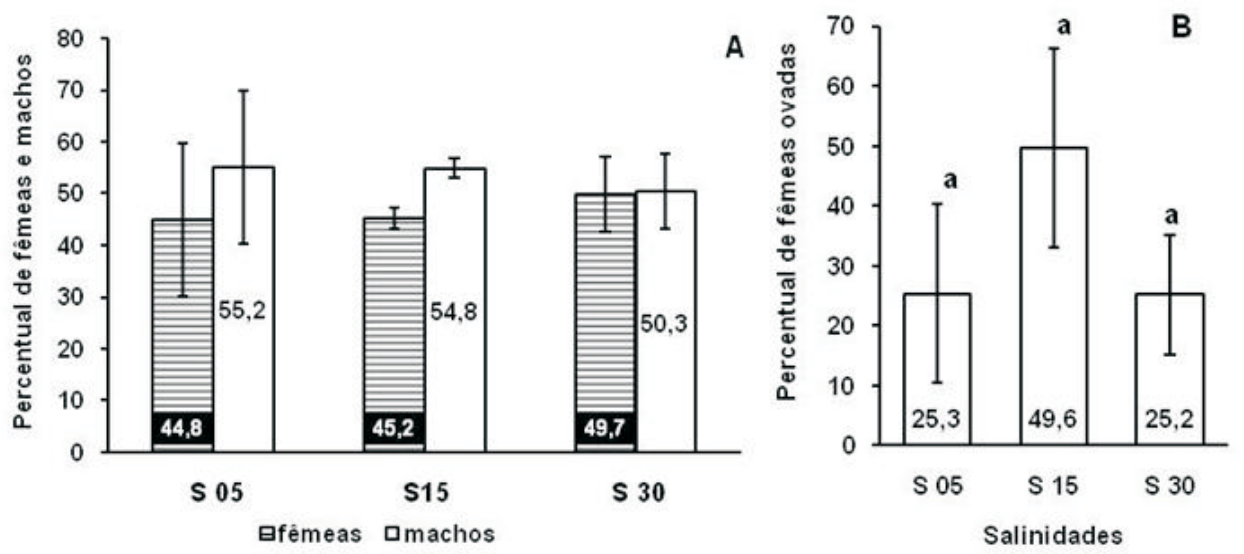

Figura 5 - Pseudodiaptomus richardi. (A) Percentuais de fêmeas e machos após 17 dias de cultivo. (B) Percentual de fêmeas ovadas no $17^{\circ}$ dia de cultivo. Salinidades 5,15 e 30 .

da incubação inicial. Ao término do experimento algumas das fêmeas estavam no decorrer da segunda e outras no início da terceira incubação.

Para a espécie $N$. incompositus não foi possível obter resultados precisos, pois as fêmeas liberavam o saco de ovos no momento em que se efetuava a observação individual diária, provavelmente devido a estresse, inviabilizando uma determinação mais precisa do tempo de incubação, sendo para essa espécie obtidos apenas valores de NOP. Além disso, ocorreu mortalidade total dos indivíduos desta espécie em S 15 e S 30.

\section{Testes de Salinidades}

Para fêmeas de $P$. richardicultivadas, os valores de PO não apresentaram diferenças estatísticas entre os tratamentos $(p>0,05)$, com médias entre 6,38 e 6,71 ovos.fêmea ${ }^{-1} \mathrm{dia}^{-1}$ (Figura 06). Porém foram superiores $(p<0,05)$ aos valores encontrados para as PO das fêmeas aclimatadas, onde as médias obtidas foram de 2,51 a 4,83 ovos. fêmea-1 dia $^{-1}$ (Figura 06). Comparando os valores de $\mathrm{PO}$ das fêmeas aclimatadas, os valores encontrados na $S 30$ foram superiores $(p<0,05)$ aos das $S 15$ e S 5 , que foram iguais entre si $(p>$ 0,05).

Para N. incompositus, na S 10 não ocorreu formação de sacos ovígeros e houve pequena sobrevivência dos organismos adultos (entre 13 e $27 \%$ ), significativamente inferior as salinidades 1 e 5 , onde a sobrevivência observada foi acima de $70 \%$ (Figura 7- A). Os valores de NOP obtidos na $S 1$ foram superiores $(p<$ 0,05 ) aos encontrados na S 5 (Figura 7- B).

Testes de Alimentação

Não foram observadas diferenças estatísticas para a $\mathrm{PO}$ de $P$. richardi sob as diferentes dietas utilizadas (Figura 8- A) e para o NOP de N. incompositus $(p>0,05)$; porém, comparando os valores de NOP obtidos para as duas espécies, as médias encontradas para $P$. richardi, entre 10,04 e 13,92 ovos.saco-1 fêmea ${ }_{1}$ foram maiores que as encontradas para $N$. incompositus, entre 0,76 e 1,16 ovos.saco-1 fêmea ${ }^{-1}$ (Figura 8- B).

\section{DISCUSSÃO}

\section{Crescimento de Pseudodiaptomus richardi}

Os resultados indicam que o copépode $P$. richardi é uma espécie verdadeiramente eurihalina, com sucesso no seu desenvolvimento de náuplio até a fase adulta nas salinidades 5, 15 e 30, com tempo médio de desenvolvimento e valores de sobrevivência final semeIhantes entre as três salinidades testadas. Este resultado corrobora a classificação de Montú (1980), que classificou a espécie como eurihalina.

Outras espécies de copépodes consideradas eurihalinas, apresentam diferentes níveis de adaptação para variações de salinidade em estuários. Eurytemora affinis é bem adaptada para baixas salinidades, já em salinidades mais elevadas apresenta maiores tempo de desenvolvimento e mortalidade, indicando estresse sob essas condições (Devreker et al., 2007). Náuplios de Acartia californiensis sofrem alta mortalidade quando incubados em baixas salinidades (Johnson, 1980). Indivíduos adultos do copépode Eurytemora velox podem sobreviver por longo tempo em água doce ou hypersalina, já os náuplios dessa espécie não conseguem completar seu desenvolvimento nessas condições (Nagajar, 1988).

Para Eurytemora affinis a sobrevivência alcançada no crescimento desde náuplio até adulto em salinidades entre 5 e 15 em temperatura $15^{\circ} \mathrm{C}$, foi entre 83 e $97,5 \%$ (Devreker et al., 2007). Para Acartia tonsa, cultivada a S 30 e $\mathrm{T}^{\circ} \mathrm{C} 25$, a sobrevivência foi entre 51 e $56 \%$ (Kaminski, 2004), valores mais próximos aos do presente estudo com $P$. richardi $(40,51 \pm 7,6 \%$, alcançando $49 \%$ na S 15$)$. 


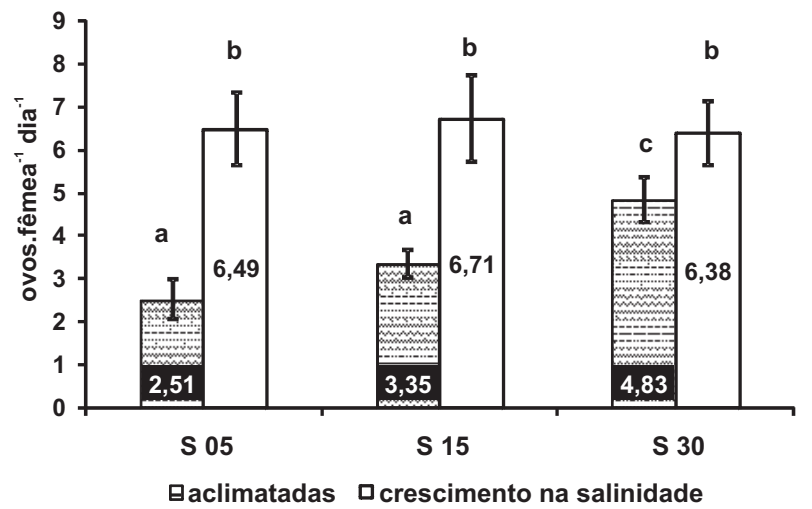

Figura 6 - Produção de ovos (ovos. fêmea ${ }^{-1}$ dia $^{-1}$ ) de Pseudodiaptomus richardi em diferentes salinidades. Média e desvio padrão. Letras minúsculas diferentes denotam diferenças significativas $(p<0,05)$. Fêmeas que passaram por aclimatação para as diferentes salinidades $x$ fêmeas crescidas na salinidade.

A mortalidade acentuada dos náuplios no início do crescimento, também se observa em outras espécies, indicando que durante o desenvolvimento larval os náuplios sofrem maior mortalidade do que os copepoditos (Kiørboe \& Sabatini, 1995). No presente estudo, observou-se que ao final da fase de náuplios e início do surgimento dos primeiros copepoditos a sobrevivência observada foi entre 53 e $64 \%$, no 5으. dia. Para o copépode Calanus helgolandicus cultivado a $15^{\circ} \mathrm{C}$ e alimentado com altas concentrações de $I$. galbana, a sobrevivência foi de $62,5 \%$ quando organismos atingiram o estágio de náuplio V (Cook et al., 2007). Durante a fase de copepoditos também observou-se mortalidade de organismos. Devreker et al. (2007) verificaram que durante o desenvolvimento de Eurytemora affinis, as maiores taxas de mortalidade ocorreram entre o estágio de náuplio $\mathrm{V}$ a copepodito III.

Em relação às medidas do prossoma obtidas para os organismos adultos ao final do experimento de crescimento, os maiores tamanhos encontrados para as fêmeas em relação aos machos, concordam com resultados encontrados para outras espécies de copépodes (Kaminski, 2004; Leandro et al., 2006).

Os valores de $\mathrm{R}^{2}$ obtidos nas curvas de regressão linear para as medidas de largura e comprimento durante o crescimento de $P$. richardi $(0,81$ e 0,9$)$ são semelhantes aos encontrados por Kaminski (2004) para o copépode $A$. tonsa $(0,83$ e 0,86$)$; indicando modelo de crescimento isocrônico para estas espécies (Mauchline, 1998). O TMD foi maior para $P$. richardi do que o encontrado para $A$. tonsa (16 dias para $P$. richardi e 7 dias para $A$. tonsa), e conseqüentemente, o valor de incremento diário de tamanho foi menor (14 e $42 \mu \mathrm{m}$ para $P$. richardi e 23 e $84 \mu \mathrm{m}$ para $A$. tonsa, largura e comprimento, respectivamente). Quando cultivada em $\mathrm{T}^{\circ} \mathrm{C} 20$ o TMD de $A$. tonsa em salinidades 15 e 30 foi de 10 dias (Cardozo, 2004). Os resultados deste estudo corroboram a idéia de que o crescimento de copépodes é de 30 a $50 \%$ mais rápido nos desovantes livres do que nos que carregam ovos (Kiørboe \& Sabatini, 1995).

O tempo de crescimento e a duração das fases de desenvolvimento podem também ser afetados pela variação da temperatura. Vários estudos observaram que o tempo de desenvolvimento de copépodes decresce com o aumento da temperatura de incubação (Leandro et al., 2006; Devreker et al., 2007). O copépode Gladioferens imparipes, espécie que carrega os ovos, leva em torno de 17 dias para se tornar maturo quando cultivado a $20^{\circ} \mathrm{C}$ (Payne \& Rippingale, 2000), tempo semelhante ao encontrado para $P$. richardino presente estudo. Para várias espécies do gênero Pseudodiaptomus o tempo de desenvolvimento pode variar entre 10 e 28 dias de acordo com a temperatura, sendo acelerado com o aumento da mesma, e em al-
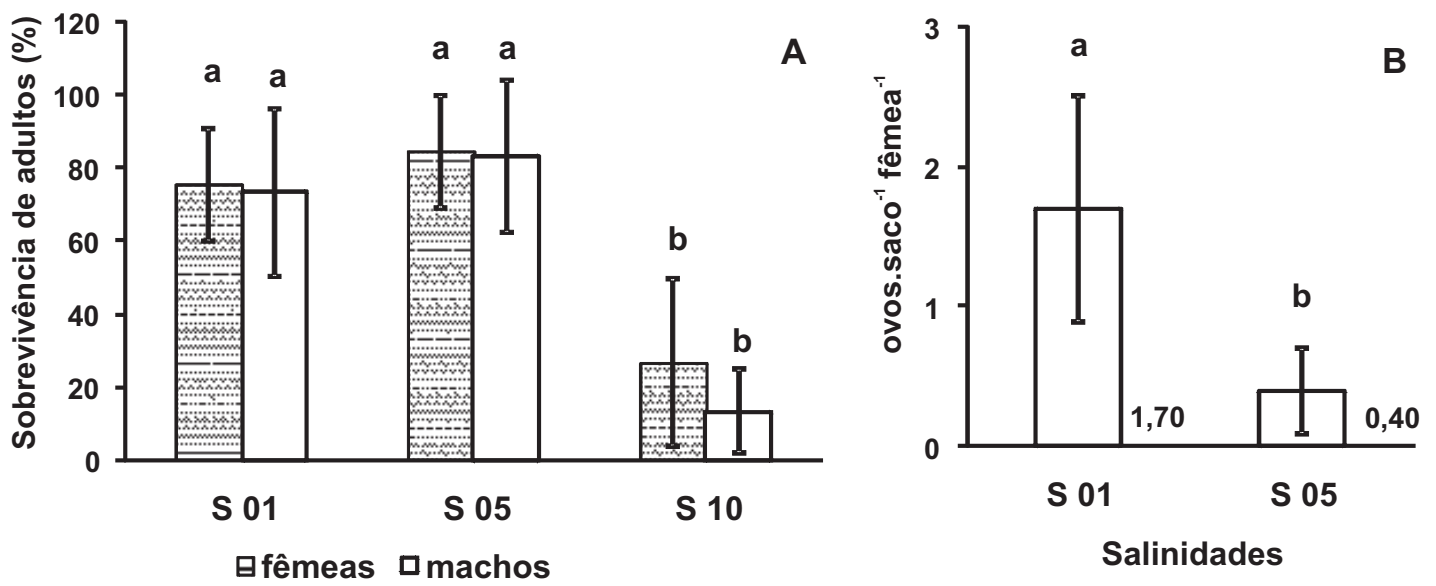

Figura 7 - Experimentos de salinidade com Notodiaptomus incompositus. (A) Percentual de sobrevivência de copépodes adultos (fêmeas de machos) após incubação de 72 horas. (B) Produção de ovos.saco-1 fêmea-1 ${ }^{-1}$ Média e desvio padrão. Letras minúsculas diferentes denotam diferenças significativas. 


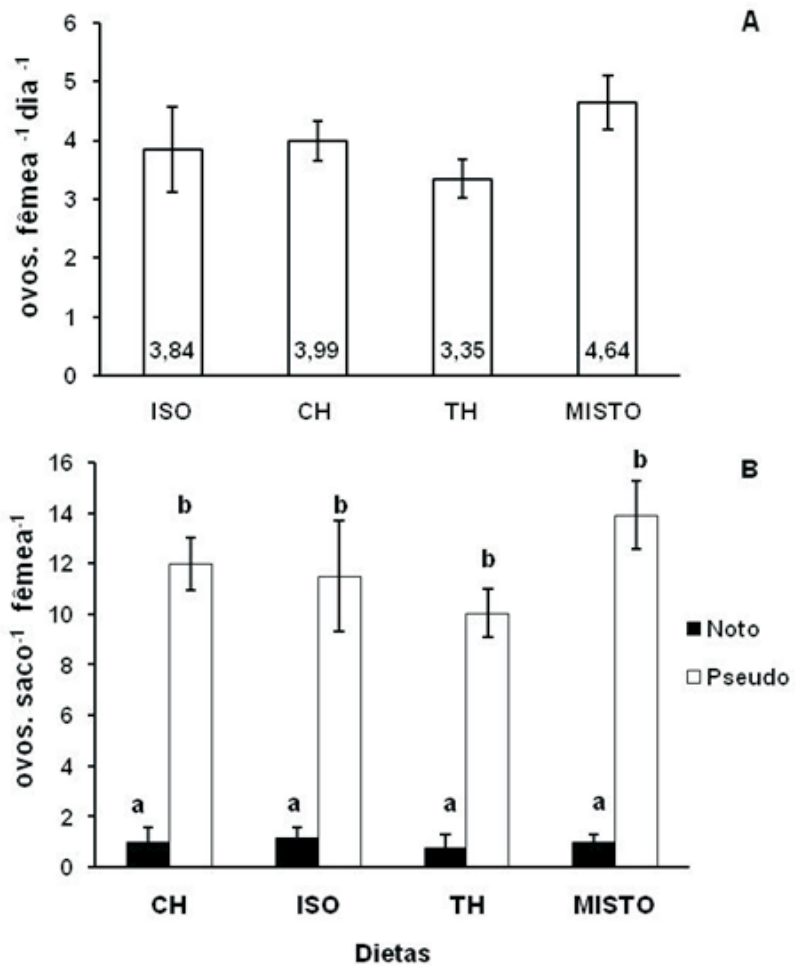

Figura 8 - (A) Produção de ovos (ovos. fêmea-1 dia $^{-1}$ ) de $P$. richardi sob diferentes dietas algais. (B) Valores de ovos.saco ${ }^{-1}$ fêmea-1 sob diferentes dietas algais para $P$. richardi (S 15) e $N$. incompositus (S 1). Média e desvio padrão. Letras minúsculas diferentes denotam diferenças significativas.

gumas espécies diferindo entre machos e fêmeas. $\mathrm{Na}$ temperatura de $20^{\circ} \mathrm{C}$, foram observados tempos de desenvolvimento de 21 dias para $P$. hessei, 23 a 24 dias para $P$. marinus e 25 dias para P. coronatus (Mauchline, 1998 - Tabela 47). A espécie $P$. hessei, quando cultivada a $23^{\circ} \mathrm{C}$ leva $17-18$ dias para completar seu desenvolvimento, mesmo tempo que $P$. richardi leva para se desenvolver quando cultivado a $20^{\circ} \mathrm{C}$. Em vista destas informações, observamos que o tempo de desenvolvimento varia de acordo com a temperatura de forma única para cada espécie.

Apesar de o TMD até a fase adulta não ter apresentado diferença estatística entre as três salinidades, nossos resultados sugerem que na $S 15$ o crescimento é um pouco mais acelerado, pois o TMD foi de 15 dias na S 15 e de 16 dias nas S 5 e S 30 . Além disso, ao final dos 17 dias de cultivo, foi observada maior média de fêmeas ovígeras na S 15. Mudanças de salinidade afetam significativamente o tempo de maturação de Gladioferens imparipes, este copépode atingiu 50\% de organismos maturos em 10,4 dias quando cultivado em S 27, e em 11,4 dias quando cultivado em S 9 (Payne \& Rippingale, 2001).

A variação de salinidade não afetou a proporção de machos e fêmeas após 17 dias de cultivo, tendo sido observadas proporções semelhantes entre os sexos nas três salinidades testadas. A composição de adultos de Pseudodiaptomus marinus, em relação a proporções de machos e fêmeas, varia irregularmente de acordo com as estações do ano, e as fêmeas geralmente são mais numerosas que os machos, compreendendo $61,4 \%$ da média anual (Liang \& Uye, 1997). No ambiente, a mortalidade das fêmeas ovígeras é devido a alta suscetibilidade destas aos predadores visuais, e para muitas espécies um maior número de fêmeas em relação a machos pode representar uma estratégia reprodutiva (Kiørboe \& Sabatini, 1994).

\section{Número de ovos produzidos pelas espécies (NOP e PO)}

O tempo médio de desenvolvimento do ovo de $P$. richardi (três dias a $20^{\circ} \mathrm{C}$ ) observado nesse estudo demonstra que a espécie apresenta uma taxa de fecundidade relativamente baixa, devido ao tempo de incubação relativamente longo, e o mesmo não parece ser afetado pela salinidade. Outra espécie do gênero, $P$. marinus, também apresenta tempo de incubação longo, variando de 1,2; 3,9 e até 10,9 dias em 28,15 e $9^{\circ} \mathrm{C}$, respectivamente (Liang \& Uye, 1997). Uma explicação para esse fato pode ser a peculiaridade de que espécies do gênero Pseudodiaptomus desenvolvem seu estágio naupliar I dentro do ovo, já eclodindo como náuplios II (Mauchline, 1998).

Segundo Kiorboe \& Sabatini (1994), copépodes que carregam ovos exibem baixa fecundidade e tempo de incubação longo quando comparados a espécies que desovam livremente, o que estaria relacionado a estratégias reprodutivas: Desovantes livres apresentam alta fecundidade para compensar a grande mortalidade dos ovos e os que carregam ovos apresentam baixa fecundidade para compensar a grande mortalidade das fêmeas. O tempo de incubação de ovos em fêmeas que desovam livremente é apenas um terço do tempo de incubação dos Cyclopoida que carregam ovos e os Calanoida que carregam ovos apresentam valores intermediários (Kiorboe e Sabatini, 1994). O intervalo entre uma desova e outra é maior nas espécies que carregam ovos, pois além de produzirem ovos maiores que as espécies que desovam livremente, uma segunda massa de ovos não pode ser formada até que os náuplios de uma incubação sejam liberados (Mauchline, 1998).

O valor médio de PO obtido para fêmeas $P$. richardi cultivadas nas salinidades testadas neste estudo (média de 6,5 ovos. fêmea-1 dia $^{-1}$ ) foi intermediário aos encontrados por Liang e Uye (1997) para P. marinus (médias de 2,3 e 12,1 ovos.fêmea-1 dia $^{-1}$, inverno e verão, respectivamente). Já para as fêmeas que passaram por aclimatação a média foi menor (3,6 ovos fêmea $\left.^{-1} \mathrm{dia}^{-1}\right)$, sugerindo que a espécie passa por estresse 
osmótico em perídodos onde ocorrem mudanças na salinidade, possivelmente gastando mais energia em atividade de osmorregulação e diminuindo o gasto com a reprodução (PO). Este resultado concorda com as observações de outros estudos (Gaudy et al., 2000; Kimmel \& Bradley, 2001; Chinnery \& Williams, 2004) que sugerem que certas espécies de copépodes ao serem expostos a variações de salinidade fora de sua faixa ótima de tolerância, apresentam maior gasto energético devido a atividade de osmorregulação.

Para Acartia tonsa, Cardozo (2004) também encontrou valores menores de PO para fêmeas aclimatadas do que para fêmeas cultivadas em determinadas salinidades, concluindo que a reprodução desta espécie pode ser afetada por variações de salinidade dentro de um curto período de tempo. Por outro lado, as taxas de PO de Acartia sinjiensis parecem não ser afetadas por diferentes salinidades, embora este parâmentro possa exercer forte impacto negativo sobre o crescimento populacional da mesma (Milione \& Zeng 2008). Já para outras espécies do gênero Acartia, Castro-Longória (2003) verificou que mudanças na salinidade podem afetar a fecundidade, algumas espécies produziram menor número de ovos em menores salinidades, além de terem sido observadas diferenças no sucesso de eclosão sob variações deste parâmetro.

Para $P$. richardi, os menores valores de PO verificados para fêmeas aclimatadas, podem também estar relacionados com a idade das mesmas; sendo que as fêmeas cultivadas eram mais jovens e possuíam idades semelhantes, enquanto que as aclimatadas provinham do cultivo estoque que continha copépodes de idades variadas.

Os valores baixos de NOP encontrados para Notodiaptomus incompositus podem ter ocorrido devido ao fato de que os testes foram realizados com organismos coletados diretamente do ambiente. Apesar de passarem por um período de adaptação e aclimatação gradativa para as outras salinidades, a NOP pode ter sido mínima devido a condições de estresse, sendo que no cultivo massivo mantido anteriormente no laboratório por 40 dias, foi observada a presença de fêmeas com maior número de ovos incubados nas salinidades 0 e 5, tanto nas fêmeas coletadas do campo como na primeira geração cultivada (F1). Porém esses valores não foram quantificados e infelizmente o cultivo sofreu mortalidade repentina.

Por outro lado, deve-se também levar em consideração que os resultados podem simplesmente estar relacionados com uma possível baixa capacidade osmorregulatória desta espécie, sendo portanto mais característicos de água doce e não adaptados a ambientes com grande oscilação de salinidade. Os resultados deste estudo não concordam com a classificação inicial proposta por Montú (1980), que classificou $N$. incompositus como eurihalino, e sim, sugerem que a mesma seja oligohalina (intervalo halino de 0,5 a 5). Os valores de NOP aqui obtidos podem não ser representativos, uma vez que embora a espécie seja registrada no ELP com certa freqüência, tem sua distribuição fortemente limitada pela salinidade, conforme observado por Kaminski et al. (em preparação, b).

Ainda que a variação da alimentação não tenha exercido influência significativa sobre a quantidade de ovos produzidos pelas duas espécies, indicando que todas as microalgas testadas tiveram a mesma eficiência nas concentrações testadas; comparando-se o NOP das duas espécies, os maiores valores foram obtidos para $P$. richardi, indicando que as microalgas utilizadas foram mais adequadas para esta espécie.

A espécie $P$. richardi demonstra bom potencial reprodutivo sob condições de laboratório. Além de ser bem adaptada as oscilações de salinidade, é também extremamente flexível em termos de alimentação, sobretudo mostrando grande eficiência em se alimentar de partículas de diferentes tamanhos (5 a $12 \mu \mathrm{m}$ ), ao contrário de Acartia tonsa, que é ineficiente na captura de partículas menores que $10 \mu \mathrm{m}$ (Berggreen et al., 1988) e tem sua PO diminuída quando alimentada com microalgas relativamente pequenas como Isocrysis sp. (Kaminski, 2004). Para a espécie N. incompositus, novos estudos são necessários para avaliar com maior precisão o potencial de cultivo e reprodutivo desta espécie sob condições de laboratório.

\section{AGRADECIMENTOS}

Agradeçemos a Capes pelo suporte com bolsa de estudo e auxilio a pesquisa, as instituições FURG e UFPR pelo suporte físico e técnico, e à equipe de trabalho do Laboratório de Zooplâncton da FURG.

\section{REFERÊNCIAS BIBLIOGRÁFICAS}

Aman, S. \& Altaff, K. 2004. Biochemical Profile of Heliodiaptomus viddus, Sinodiaptomus (Rhinediaptomus) indicus, and Mesocyclops aspericornis and their Dietary Evaluation for Postlarvae of Macrobrachium rosenbergii. Zool. Stud. 43(2):267-275.

Berggreen, U.; Hansen, B. \& Kiorboe, T. 1988. Food size spectra, ingestion and growth of the copepod Acartia tonsa during development: implications for determination of copepod production. Mar. Biol. 99: 341-352.

Cardozo, A.P. 2004. Influência de diferentes salinidades na reprodução e crescimento de Acartia tonsa (Copepoda Calanoida). Monografia de Graduação. 
Fundação Universidade Federal do Rio Grande, RS, Brasil. 23p.

Cardozo, A.P.; Bersano, J.G.F. \& Amaral, W.J.A. 2007. Composition, Density and Biomass of Zooplankton in Culture Ponds of Litopenaeus vannamei (DECAPODA:PENAEIDAE) in Southern Brazil. Braz. J. Aquat. Sci. Technol., 2007, 11(1):13-20.

Castro-Longoria, E. 2003. Egg Production and hatching success of four Acartia species under different temperature and salinity regimes. J. Crust. Biol. 23(2):289-299.

Centeno, A.J. 1999. Curso de estatística aplicada à biologia. 2. Ed. Goiânia, Ed. da UFG. 234 p.

Chinnery, F.E. \& Williams, J.A. 2004. The influence of temperature and salinity on Acartia (Copepoda: Calanoida) nauplii survival. Mar. Biol. 145:733-738.

Cook, K.B.; Bunker, A.; Hay, S.; Hirst, A.G. \& Speirs, D.C. 2007. Naupliar development times and survival of the copepods Calanus helgolandicus and Calanus finmarchicus in relation to food and temperature. J. Plankton Res. 29 (9):757-767.

Coyle, K. O. \& Pinchuk, A. I., 2003. Annual cycle of zooplankton abundance, biomass and production on the northern Gulf of Alaska shelf, October 1997 through October 2000. Fish. Oceanogr. 12(4/5), 327338.

Devreker, D.; Souissi, S.; Forget-Leray, J. \& Leboulenger, F. 2007. Effects of salinity and temperature on the post-embryonic development of Eurytemora affinis (Copepoda; Calanoida) from the Seine estuary: a laboratory study. J. Plankton Res. 29 (supplement I): i117-i113.

Duarte, A.K.; Gloeden, I. \& Resgalla, C.Jr. 1991. Flutuações Espaciais e Temporais da Comunidade Zooplanctônica da Lagoa dos Patos (RS, BRASIL). Biol. Acuática. 15:126-127.

Garcia, C.A.E. 1997. Hydrographic Characteristics. In: Seeliger, U.; Odebrecht, C. \& Castello, J.P. (eds.). Subtropical Convergence Environments. Springer,Berlin. 18-20pp.

Gaudy, R.; Cervetto, G. \& Pagano, M. 2000. Comparison of the metabolism of Acartia clausi and A. tonsa: influence of temperature and salinity. J. Exp. Mar. Biol. Ecol. 247:51-65.

Harris, R.P.; Wiebe, P.H.; Lenz. J.; Skjoldal, H.R. \& Huntley, M. 2000. ICES Zooplankton Methodology Manual. Academic Press. London. 684p.

Hillebrand, H.; Dürselen, C.D.; Kirschtel, D.; Pollingher, U. \& Zohary, T. 1999. Biovolume Calculation for Pelagic and Benthic Microalgae. J. Phycol. 35:403424.

Hoffmeyer, M.S. 2004. Decadal change in zooplankton seasonal succession in the Bahía Blanca estuary, Argentina, following introduction of two zooplankton species. J. Plankton Res. 26(2):181-189.
Hopcroft, R.R. \& Roff, J.C. 1998. Zooplankton growth rates: the influence of size in nauplii of tropical marine copepods. Mar. Biol. 132: 87-96.

Irigoien, X.; Head, R.N.; Harris, R.P.; Cummings, D. \& Harbour, D. 2000. Feeding selectivity and egg production of Calanus helgolandicus in the English Channel. Limnol. Oceanogr. 45(1): 44-54.

Johnson, J.K. 1980. Effects of temperature and salinity on production and hatching of dormant eggs of Acartia californiensis (Copepoda) in an Oregon estuary. Fish. Bull. (Wash DC) 77: 567-584.

Kaminski, S.M. 2004. Influência da Alimentação sobre a Reprodução e o Desenvolvimento do Copépode Calanoida Acartia tonsa Dana 1849, em Cultivo Intensivo. Dissertação de Mestrado. Universidade Federal de Santa Catarina- UFSC, Santa Catarina. $55 p$.

Kaminski, S.M.; Bersano, J.G.F. \& Amaral, W.J.A. (em preparação, a). Variação Sazonal e Interanual do Mesozooplâncton de Áreas Rasas do Estuário da Lagoa dos Patos e Região Costeira Adjacente, Rio Grande - RS, Brasil, Durante Período de 2000 2005.

Kaminski, S.M.; Bersano, J.G.F. \& Amaral, W.J.A. (em preparação, b). Distribuição e variação sazonal e interanual (2000 a 2005) dos copépodes Acartia tonsa, Pseudodiaptomus richardie Notodiaptomus incompositus no Estuário da Lagoa dos Patos e Praia do Cassino - Rio Grande - RS.

Kimmel, D. G. \& Bradley, B. P. 2001. Specific protein responses in the calanoid copepod Eurytemora affinis (Poppe, 1880) to salinity and temperature variation. J. Exp. Mar. Biol. Ecol. 266:135-149.

Kiørboe, T.; Møhlenberg, F. \& Hamburger, K. 1985. Bioenergetics of the planktonic copepod Acartia tonsa: relation between feeding, egg production and respiration, and composition of specific dynamic action. Mar. Ecol. Prog. Ser. 26:85-97.

Kiørboe, T. \& Sabatini, M. 1994. Reproductive and life cycle strategies in egg-carrying and free-spawning calanoid copepods. J. Plankton Res. 16:1353-1366.

Kiørboe, T. \& Sabatini, M. 1995. Scaling of fecundity, growth and development in marine planktonic copepods. Mar. Ecol. Prog. Ser. 120:285-298.

Kleppel, G.S. 1992. Environmental regulation of feeding and egg production by Acartia tonsa off southern Califórnia. Mar. Biol. 112: 57-65.

Liang, D. \& Uye, S. 1997. Seasonal reproductive biology of the egg-carrying calanoid copepod Pseudodiaptomus marinus in a eutrophic inlet of the Inland Sea of Japan. Mar. Biol. 128: 409-414.

Leandro, S.M.; Tiselius, P. \& Queiroga, H. 2006. Growth and development of nauplii and copepodites of the estuarine copepod Acartia tonsa from southern 
Europe (Ria de Aviero, Portugal) under saturating food conditions. Mar. Biol. 150: 121-129.

Lopes, R.M.1994. Zooplankton distribution in the Guaraú river estuary (South-eastern Brazil). Estuar. Coast. Shelf Sci. 39: 287-302.

Magalhães, A.; Costa, R.M.; Liang, T.H.; Pereira, L.C.C. \& Ribeiro, M.J.S. 2006. Spatial and temporal distribution in density and biomass of two Pseudodiaptomus species (Copepoda: Calanoida) in the Caeté river estuary (Amazon Region - North of Brazil). Braz. J. Biol., 66(2A):421-430.

Mauchline, J. 1998. The biology of calanoid copepods. In: Blaxter, J. H. S., Southward, A. J., Tyler, P. A. (eds.). Advances in marine biology. Academic Press. London. 710p.

McKinnon, A.D.; Duggan, S.; Nichols, P.D.; Rimmer, M.A.; Semmens, G. \& Robino, B. 2003. The potential of paracalanid copepods as live feeds in aquaculture. Aquaculture. 223: 89-106

Milione, M. \& Zeng, C. 2008. The effects of temperature and salinity on population growth and egg hatching success of the tropical calanoid copepod, Acartia sinjiensis. Aquaculture(2008), doi: 10.1016/ j.aquaculture.2007.12.010.

Montú, M. 1980. Zooplâncton do estuário da Lagoa dos Patos I. Estrutura e variações temporais e especiais da comunidade. Atlântica. 4: 53-72.

Montú, M. \& Gloeden, I.M. 1986. Atlas dos Cladocera e Copepoda (Crustacea) do Estuário da Lagoa dos Patos ( Rio Grande, Brasil ), Nerítica, Pontal do Sul, PR. 1 (2): 1-134.

Nagajar, M. 1988. Combined effects of temperature and salinity on the complete development of Eurytemora velox (Crustacea:Calanoida). Mar Biol. 99: 353-358. Niencheski, L.F.H. \& Baumgarten, M.G. 1997. Environmental Chemistry. In: Seeliger, U.;Odebrecht, C. \& Castello, J.P. (Eds.), Subtropical Convergence Environments. Springer, Berlin. 20-24pp.
Payne, M.F.\& Rippingale, R.J. 2000. Evaluation of diets for culture of the calanoid copepod Gladioferens imparipes. Aquaculture. 187:85-96.

Payne, M.F. \& Rippingale, R.J. 2001. Effects of salinity, cold storage and enrichment on the calanoid copepod Gladioferens imparipes. Aquaculture, 201:251-262.

Payne, M.F.; Rippingale, R.J. \& Cleary, J.J. 2001. Cultured copepods as food for West Australian dhufish (Glaucosoma hebraicum) and pink snapper (Pagrus auratus) larvae. Aquaculture. 194:137-150.

Rudorff, F.M. 2002. Sazonalidade e biomassa dos Copépodos planctônicos Acartia tonsa e Notodiaptomus incompositus no estuário da Lagoa dos Patos e áreas costeiras próximas (RS-Brasil). Monografia de Graduação. Fundação Universidade Federal do Rio Grande, RS. Brasil. 52p.

Schipp, G.R.; Bosmans, J.M.P. \& Marshall, A.J., 1999. A method for hatchery culture of tropical calanoid copepods, Acartia spp. Aquaculture. 174: 81-88.

Uye, S. 1991.Temperature-dependent development and growth of the planktonic copepod Paracalanus sp. In the laboratory. Bull Plankton Soc Jpn[spec vol]: 627-636.

Uye, S.; Shimazu, T.; Yamamuro, M.; Ishitobi, Y. \& Kamiya, H. 2000. Geographical and seasonal variations in mesozooplankton abundance and biomass in relation to environmental parameters in Lake Shinji-Ohashi River-Lake Nakaumi brackishwater system, Japan. J. Mar. Syst. 26: 193-207.

Submetido: Julho/2008 Revisado: Novembro/2008 Aceito: Dezembro/2008 